\title{
ECONOMIC AND PERFORMANCE EVALUATION OF STOCHASTIC MODEL ON A BASE TRANSCEIVER SYSTEM CONSIDERING VARIOUS OPERATIONAL MODES AND CATASTROPHIC FAILURES
}

\author{
Rajeev Kumar and Sunny Kapoor \\ Department of Mathematics, Maharishi Dayanand University, Rohtak, Haryana, India
}

Received 2013-05-15; Revised 2013-06-29; Accepted 2013-07-22

\begin{abstract}
In this study a stochastic model for a Base Transceiver System (BTS) is proposed that consists of various hardware and software components. A Base Transceiver System (BTS) may undergoes four modes during its operation viz normal, congestion, down and failure mode. The hardware and software components may have various types of major and minor faults. The occurrence of a minor fault leads to partial failure whereas a major fault and catastrophic failure leads to complete failure of the system. That may have various types of faults including major and minor faults. The aspect that a failure in hardware component, sometimes, leads to software failure in the system is also incorporated. On failure, the technicians first inspect whether there is hardware or software or hardware based software failure then recovery of the relevant component is done. Using Markov processes and regenerative point technique various measures of system performance are obtained. On the basis of these measures the profit analysis of the system is carried out. Various conclusions about reliability, performance and profit of the system are made on the basis of the graphical studies.
\end{abstract}

Keywords: Base Transceiver System (BTS), Hardware Based Software Fault, Catastrophic Failure, Mean Time to System Failure, Expected Uptime, Expected Congestion Time, Profit, Markov Process and Regenerative Point Technique

\section{INTRODUCTION}

Mobile system operators are emphasizing the need of uninterrupted service from cellular systems. Longer service life requirements, reduced periodic maintenance and less frequent checkouts are pushing the envelope of system availability requirements while at the same time systems are becoming more complex. As mobile phones have penetrated in almost all aspects of human life, so reliability is going to be prime issue for mobile operators as well as researchers. A Base Transceiver Station (BTS) is the most important networking component of mobile communication system from which all signals are sent and received and consists of both hardware and software components. A BTS is also called Base Station (BS) and is commonly referred to as 'cell phone tower'. A BTS will have between 1 and 16 Transceivers (TRX) depending on the geography and user demand of an area.

BTS may fails, either due to some hardware fault or software fault or hardware based software fault or catastrophic failure. The hardware faults include Voltage Standing Wave Ratio (VSWR) fail, AC failure, optical fiber cut, fan tray damage, double Duplexer timing and Management Unit (DTMU), double Duplexer Transmitting and Receiving Unit (DTRU), double Duplexer Amplifier Unit (DATU), Double Duplexer Power Unit (DDPU) fail whereas software faults include software fault in DTRU, DDPU, DATU, DTMU, transport device. Here hardware based software faults are those software faults which occur due to improper functioning or failure of hardware components, like software fault in DDPU, DTRU, DATU, DTMU and 
Transport device like fault in optical fiber component leads to improper working of DTMU. Catastrophic failure are due to power failure, storms, floods, earthquakes the network may not provide its service continuously to its subscribers. In case of occurrence of major fault, there is complete failure of system whereas in case of minor fault system performance and capacity may decrease. Moreover when there is saturation or congestion of calls in BTS then the services for some subscribers of network is reduced or calls are unattended. BTS supports the air interface connection with mobiles so its reliability, availability and cost plays a very significant role in mobile systems and hence need to be analyzed.

In the field of reliability modeling several researchers Gupta and Kumar (1983); Gopalan and Murlidhar (1991); Gopalan and Bhanu (1995); Rizwan and Taneja (2000); Taneja et al. (2004); Kumar et al. (2010); Kumar and Bhatia (2011) and Kumar and Rani (2013) analyzed a large number of systems considering various concepts such as different failure modes, repairs, replacements, inspections, different operational stages however none of the researcher has carried out the analysis of BTS considering the above aspects. For hardware-software systems, Welke et al. (1995); Teng et al. (2006); Tumer and Smidts (2011); Kumar and Kapoor (2012) discussed various types of hardware and software failures. Recently Kumar and Kapoor (2013) carried out the profit evaluation of a stochastic model on base transceiver system considering software based hardware failures and congestion of calls. However none of the researcher has carried out the analysis of BTS considering the hardware based software failure and catastrophic failure.

\subsection{Other Assumptions}

- A minor or major fault may be in a pure hardware or pure software or hardware based software components

- In the system congestion of calls takes place at any time and system restore from it with the passage of time

- The technicians are available immediately at BTS site to handle all types of faults

- Rates of occurrence of fault/failure, congestion and system restoration are constant whereas repair and inspection time distributions are arbitrary

- The system is as good as new after each repair/replacement

- Switching is perfect and instantaneous

- All random variables are mutually independent

\section{Notations}

$\mathrm{O} / \mathrm{O}_{\mathrm{c}}$ $\mathrm{O}_{\mathrm{i}} / \mathrm{F}$

Operative/Congestion state

Down state/Failed state under inspection

\begin{tabular}{|c|c|}
\hline $\mathrm{O}_{\mathrm{h}_{\mathrm{r}}} / \mathrm{O}_{\mathrm{s}_{\mathrm{r}}}$ & $\begin{array}{l}\text { Down state due to hardware/software } \\
\text { fault under repair }\end{array}$ \\
\hline $\mathrm{O}_{\mathrm{hs}_{\mathrm{r}}}(\mathrm{t}) / \mathrm{F}_{\mathrm{hs}_{\mathrm{r}}}(\mathrm{t})$ & $\begin{array}{l}\text { Down state/Failed state due to hardware } \\
\text { based software fault under repair }\end{array}$ \\
\hline $\mathrm{F}_{\mathrm{h}_{\mathrm{r}}} / \mathrm{F}_{\mathrm{s}_{\mathrm{r}}}$ & $\begin{array}{l}\text { Failed state due to hardware/software } \\
\text { fault under repair }\end{array}$ \\
\hline$\lambda_{1} / \lambda_{2}$ & Rate of occurrence of major/minor faults \\
\hline & $\begin{array}{l}\text { Rate of occurrence of hardware based } \\
\text { major/minor software faults }\end{array}$ \\
\hline$\eta$ & Rate of congestion of calls \\
\hline$\alpha$ & $\begin{array}{l}\text { Rate with which system restored after } \\
\text { Congestion }\end{array}$ \\
\hline$a_{1} / a_{2}$ & $\begin{array}{l}\text { Probability that the major/minor } \\
\text { hardware fault occurs in the system }\end{array}$ \\
\hline $\mathrm{b}_{1} / \mathrm{b}_{2}$ & $\begin{array}{l}\text { Probability that the major/minor software } \\
\text { fault occurs in the system }\end{array}$ \\
\hline $\mathrm{c}_{1} / \mathrm{c}_{2}$ & $\begin{array}{l}\text { Probability that the hardware based } \\
\text { Major/minor software fault occurs in the } \\
\text { system }\end{array}$ \\
\hline $\mathrm{d}_{1}$ & $\begin{array}{l}\text { Probability that the catastrophic failure } \\
\text { occurs in the system }\end{array}$ \\
\hline $\mathrm{q}_{\mathrm{ij}}(\mathrm{t}) / \mathrm{Q}_{\mathrm{ij}}(\mathrm{t})$ & $\begin{array}{l}\text { Probability of transitions from state ' } \mathrm{i} \text { ' to } \\
\text { state ' } \mathrm{j} \text { ' }\end{array}$ \\
\hline $\mathrm{g}_{\mathrm{h}_{1}}(\mathrm{t}) / \mathrm{g}_{\mathrm{h}_{2}}(\mathrm{t})$ & $\begin{array}{l}\text { P.d.f. of repair time of major/minor } \\
\text { hardware Fault }\end{array}$ \\
\hline $\mathrm{g}_{\mathrm{s}_{1}}(\mathrm{t}) / \mathrm{g}_{\mathrm{s}_{2}}(\mathrm{t})$ & $\begin{array}{l}\text { P.d.f. of repair time of major/minor } \\
\text { software Fault }\end{array}$ \\
\hline $\mathrm{g}_{\mathrm{h}_{3}}(\mathrm{t}) / \mathrm{g}_{\mathrm{h}_{4}}(\mathrm{t})$ & $\begin{array}{l}\text { P.d.f. of repair time of hardware based } \\
\text { major/minor software fault }\end{array}$ \\
\hline $\mathrm{g}_{\mathrm{c}_{\mathrm{f}}}(\mathrm{t}) / \mathrm{G}_{\mathrm{c}_{\mathrm{f}}}(\mathrm{t})$ & f of repair time of catastrophic \\
\hline $\mathrm{i}_{1}(\mathrm{t}) / \mathrm{i}_{2}(\mathrm{t})$ & $\begin{array}{l}\text { P.d.f. of inspection time of major/minor } \\
\text { fault }\end{array}$ \\
\hline $\mathrm{I}_{1}(\mathrm{t}) / \mathrm{I}_{2}(\mathrm{t})$ & $\begin{array}{l}\text { C.d.f. of inspection time of major/minor } \\
\text { fault }\end{array}$ \\
\hline $\mathrm{G}_{\mathrm{h}_{1}}(\mathrm{t}) / \mathrm{G}_{\mathrm{h}_{2}}(\mathrm{t})$ & $\begin{array}{l}\text { C.d.f. of repair time of major/minor } \\
\text { hardware Fault }\end{array}$ \\
\hline $\mathrm{G}_{\mathrm{s}_{1}}(\mathrm{t}) / \mathrm{G}_{\mathrm{s}_{2}}(\mathrm{t})$ & $\begin{array}{l}\text { C.d.f. of repair time of major/minor } \\
\text { software fault }\end{array}$ \\
\hline $\mathrm{G}_{\mathrm{h}_{3}}(\mathrm{t}) / \mathrm{G}_{\mathrm{h}_{4}}(\mathrm{t})$ & $\begin{array}{l}\text { C.d.f. of repair time of hardware based } \\
\text { major/minor software fault }\end{array}$ \\
\hline
\end{tabular}

\subsection{Model}

A transition diagram showing the various states of transition is shown as Fig. 1. The epochs of entry in to state $0,1,2,3,4,5,6,7,8,9,10$ are regenerative points, i.e., all the states are regenerative states. 


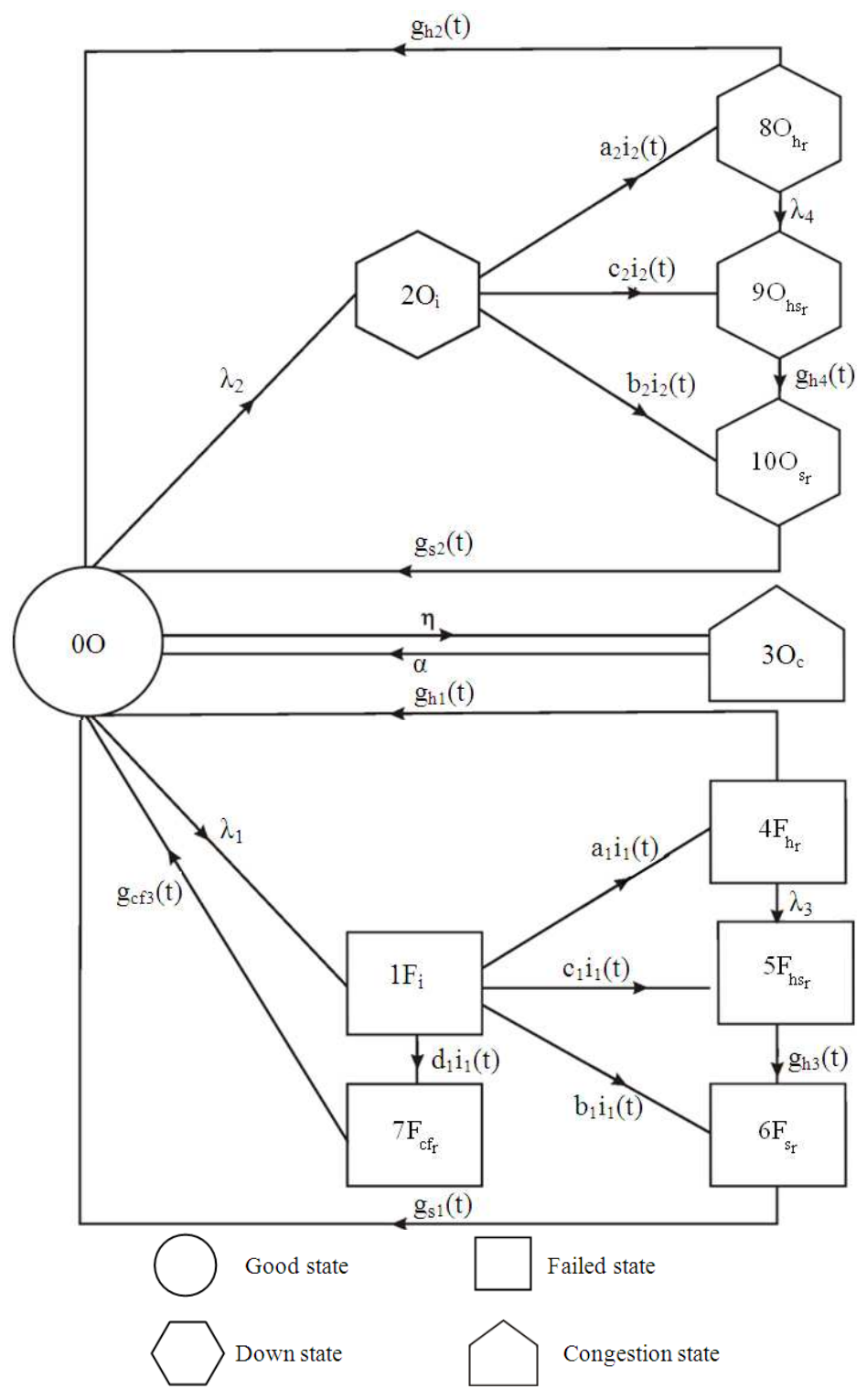

Fig. 1. State transition diagram

\subsection{Transition Probabilities and Mean Sojourn} Times

The transition probabilities are:

$$
\begin{aligned}
\mathrm{q}_{01}(\mathrm{t}) & =\lambda_{1} \mathrm{e}^{-\left(\lambda_{1}+\lambda_{2}+\eta\right) \mathrm{t}} \\
\mathrm{q}_{03}(\mathrm{t}) & =\eta \mathrm{e}^{-\left(\lambda_{1}+\lambda_{2}+\eta\right) \mathrm{t}} \\
\mathrm{q}_{15}(\mathrm{t}) & =\mathrm{c}_{1} \mathrm{i}_{1}(\mathrm{t}) \\
\mathrm{q}_{17}(\mathrm{t}) & =\mathrm{d}_{1} \mathrm{i}_{1}(\mathrm{t}) \\
\mathrm{q}_{29}(\mathrm{t}) & =\mathrm{c}_{2} \mathrm{i}_{2}(\mathrm{t})
\end{aligned}
$$

$$
\begin{aligned}
& \mathrm{q}_{02}(\mathrm{t})=\lambda_{2} \mathrm{e}^{-\left(\lambda_{1}+\lambda_{2}+\eta\right) t} \\
& \mathrm{q}_{14}(\mathrm{t})=\mathrm{a}_{1} \mathrm{i}_{1}(\mathrm{t}) \\
& \mathrm{q}_{16}(\mathrm{t})=\mathrm{b}_{1} \mathrm{i}_{1}(\mathrm{t}) \\
& \mathrm{q}_{28}(\mathrm{t})=\mathrm{a}_{2} \mathrm{i}_{2}(\mathrm{t}) \\
& \mathrm{q}_{210}(\mathrm{t})=\mathrm{b}_{2} \mathrm{i}_{2}(\mathrm{t})
\end{aligned}
$$

$$
\begin{aligned}
& \mathrm{q}_{40}(\mathrm{t})=\mathrm{e}^{-\lambda_{3} \mathrm{t}} \mathrm{g}_{\mathrm{h}_{1}}(\mathrm{t}) \\
& \mathrm{q}_{56}(\mathrm{t})=\mathrm{g}_{\mathrm{h}_{3}}(\mathrm{t}) \\
& \mathrm{q}_{70}(\mathrm{t})=\mathrm{g}_{\mathrm{c}_{\mathrm{f}}}(\mathrm{t}) \\
& \mathrm{q}_{89}(\mathrm{t})=\lambda_{4} \mathrm{e}^{-\lambda_{4} \mathrm{t}} \overline{\mathrm{G}}_{\mathrm{h}_{2}}(\mathrm{t}) \\
& \mathrm{q}_{100}(\mathrm{t})=\mathrm{g}_{\mathrm{s}_{2}}(\mathrm{t})
\end{aligned}
$$

The non-zero elements $\mathrm{p}_{\mathrm{ij}}=\lim _{\mathrm{s} \rightarrow 0} \mathrm{q}_{\mathrm{ij}}{ }^{*}(\mathrm{~s})$ are obtained as under: 


$$
\begin{array}{ll}
\mathrm{p}_{01}=\frac{\lambda_{1}}{\lambda_{1}+\lambda_{2}+\eta} & \mathrm{p}_{02}=\frac{\lambda_{2}}{\lambda_{1}+\lambda_{2}+\eta} \\
\mathrm{p}_{03}=\frac{\eta}{\lambda_{1}+\lambda_{2}+\eta} & \mathrm{p}_{14}=\mathrm{a}_{1} \mathrm{i}_{1}^{*}(0) \\
\mathrm{p}_{15}=\mathrm{c}_{1} \mathrm{i}_{1}^{*}(0) & \mathrm{p}_{16}=\mathrm{b}_{1} \mathrm{i}_{1}^{*}(0) \\
\mathrm{p}_{17}=\mathrm{d}_{1} \mathrm{i}_{1}^{*}(0) & \mathrm{p}_{28}=\mathrm{a}_{2} \mathrm{i}_{2}^{*}(0) \\
\mathrm{p}_{29}=\mathrm{c}_{2} \mathrm{i}_{2}^{*}(0) & \mathrm{p}_{210}=\mathrm{b}_{2} \mathrm{i}_{2}^{*}(0) \\
\mathrm{p}_{30}=1 & \mathrm{p}_{40}=\mathrm{g}_{\mathrm{h}_{1}}^{*}\left(\lambda_{3}\right) \\
\mathrm{p}_{45}=1-\mathrm{g}_{\mathrm{h}_{1}}^{*}\left(\lambda_{3}\right) & \mathrm{p}_{56}=\mathrm{g}_{\mathrm{h}_{3}}^{*}(0) \\
\mathrm{p}_{60}=\mathrm{g}_{\mathrm{s}_{1}}^{*}(0) & \mathrm{p}_{70}=\mathrm{g}_{\mathrm{c}_{\mathrm{f}}}^{*}(0) \\
\mathrm{p}_{80}=\mathrm{g}_{\mathrm{h}_{2}}^{*}\left(\lambda_{4}\right) & \mathrm{p}_{89}=1-\mathrm{g}_{\mathrm{h}_{2}}^{*}\left(\lambda_{4}\right) \\
\mathrm{p}_{910}=\mathrm{g}_{\mathrm{h}_{4}}^{*}(0) & \mathrm{p}_{100}=\mathrm{g}_{\mathrm{s}_{2}}^{*}(0)
\end{array}
$$

By these transition probabilities, it can be verified that:

$\mathrm{p}_{01}+\mathrm{p}_{02}+\mathrm{p}_{03}=\mathrm{p}_{14}+\mathrm{p}_{15+} \mathrm{p}_{16}+\mathrm{p}_{17}=\mathrm{p}_{28}+\mathrm{p}_{29}+\mathrm{p}_{210}=1$ $\mathrm{p}_{40}+\mathrm{p}_{45}=\mathrm{p}_{80}+\mathrm{p}_{89}=\mathrm{p}_{30}=\mathrm{p}_{56}=\mathrm{p}_{60}=\mathrm{p}_{70}=\mathrm{p}_{910}=\mathrm{p}_{100}=1$

The mean sojourn time $\left(\mu_{\mathrm{i}}\right)$ in the regenerative state $\mathrm{i}$ is defined as the time of stay in that state before transition to any other state. If $\mathrm{T}$ denotes the sojourn time in regenerative state $i$, then:

$$
\begin{array}{ll}
\mu_{0}=\frac{1}{\lambda_{1}+\lambda_{2}+\eta} & \mu_{1}=-\mathrm{i}_{1}{ }^{*^{\prime}}(0) \\
\mu_{2}=-\mathrm{i}_{2}{ }^{*^{\prime}}(0) & \mu_{3}=\frac{1}{\alpha} \\
\mu_{4}=\frac{1}{\lambda_{3}}\left(1-\mathrm{g}_{\mathrm{h}_{1}}^{*}\left(\lambda_{3}\right)\right) & \mu_{5}=-\mathrm{g}_{\mathrm{h}_{3}}^{* \prime}(0) \\
\mu_{6}=-\mathrm{g}_{\mathrm{s}_{1}}{ }^{\prime \prime}(0) & \mu_{7}=-\mathrm{g}_{\mathrm{c}_{\mathrm{f}}}^{*}(0) \\
\mu_{8}=\frac{1}{\lambda_{4}}\left(1-\mathrm{g}_{\mathrm{h}_{2}}^{*}\left(\lambda_{4}\right)\right) & \mu_{9}=-\mathrm{g}_{\mathrm{h}_{4}}^{* \prime}(0) \\
\mu_{10}=-\mathrm{g}_{\mathrm{s}_{2}}{ }^{*}(0) &
\end{array}
$$

Thus:

$$
\begin{array}{ll}
\mathrm{m}_{01}+\mathrm{m}_{02}+\mathrm{m}_{03}=\mu_{0} & \mathrm{~m}_{14}+\mathrm{m}_{15}+\mathrm{m}_{16}=\mu_{1} \\
\mathrm{~m}_{27}+\mathrm{m}_{28}=\mu_{2} & \mathrm{~m}_{30}=\mu_{3} \\
\mathrm{~m}_{40}=\mu_{4} & \mathrm{~m}_{50}+\mathrm{m}_{59}=\mu_{5} \\
\mathrm{~m}_{60}=\mu_{6} & \mathrm{~m}_{70}=\mu_{7} \\
\mathrm{~m}_{80}+\mathrm{m}_{810}=\mu_{8} & \mathrm{~m}_{90}=\mu_{9}
\end{array}
$$$$
\mathrm{m}_{100}=\mu_{10}
$$

\subsection{Mean Time to System Failure}

To determine the MTSF of the system, we regard the failed states of the system as absorbing states. By probabilistic arguments, we obtain the following recursive relations for $\phi_{\mathrm{i}}(\mathrm{t})$, c.d.f of the first passage time from regenerative state $\mathrm{i}$ to failed state:

$$
\begin{aligned}
& \phi_{0}(\mathrm{t})=\mathrm{Q}_{01}(\mathrm{t})+\mathrm{Q}_{02}(\mathrm{t}){ }^{\mathbb{S}} \phi_{2}(\mathrm{t})+\mathrm{Q}_{03}(\mathrm{t})^{\mathbb{S}} \phi_{3}(\mathrm{t}) \\
& \phi_{2}(\mathrm{t})=\mathrm{Q}_{28}(\mathrm{t})^{\mathbb{S}} \phi_{8}(\mathrm{t})+\mathrm{Q}_{29}(\mathrm{t})^{\mathrm{S}} \phi_{9}(\mathrm{t})+\mathrm{Q}_{210}(\mathrm{t})^{\mathbb{S}} \phi_{10}(\mathrm{t}) \\
& \phi_{3}(\mathrm{t})=\mathrm{Q}_{30}(\mathrm{t})^{\mathrm{S}} \phi_{0}(\mathrm{t}) \\
& \phi_{8}(\mathrm{t})=\mathrm{Q}_{89}(\mathrm{t})^{\mathbb{S}} \phi_{9}(\mathrm{t})+\mathrm{Q}_{80}(\mathrm{t})^{\mathbb{S}} \phi_{0}(\mathrm{t}) \\
& \phi_{9}(\mathrm{t})=\mathrm{Q}_{910}(\mathrm{t}) \phi_{10}(\mathrm{t}) \\
& \phi_{10}(\mathrm{t})=\mathrm{Q}_{100}(\mathrm{t})^{\mathbb{S}} \phi_{0}(\mathrm{t})
\end{aligned}
$$

Using Laplace Stieltjes transforms, the above recursive relations are solved in terms of $\phi_{0}^{* *}(\mathrm{~s})$.

The Mean Time to System Failure (MTSF) when the system starts from the state 0 , is:

$$
\mathrm{T}_{0}=\lim _{\mathrm{s} \rightarrow 0} \frac{1-\phi_{0}^{* *}(\mathrm{~s})}{\mathrm{s}}=\frac{\mathrm{N}}{\mathrm{D}}
$$

Where:

$\begin{aligned} \mathrm{N}= & \mu_{0}+\mathrm{p}_{02} \mu_{2}+\mathrm{p}_{03} \mu_{3}+\mathrm{p}_{02} \mathrm{p}_{28} \mu_{8}+\left(\mathrm{p}_{02} \mathrm{p}_{28} \mathrm{p}_{89}+\mathrm{p}_{02} \mathrm{p}_{29}\right) \mu_{9} \\ & +\left(\mathrm{p}_{02} \mathrm{p}_{28} \mathrm{p}_{89}+\mathrm{p}_{02} \mathrm{p}_{29}+\mathrm{p}_{02} \mathrm{p}_{210}\right) \mu_{10}\end{aligned}$ $\mathrm{D}=1-\mathrm{p}_{02}\left(\mathrm{p}_{28} \mathrm{p}_{80}+\mathrm{p}_{28} \mathrm{p}_{89}+\mathrm{p}_{29}+\mathrm{p}_{210}\right)-\mathrm{p}_{03}$

\subsection{Other Measures of System Performance}

Using probabilistic arguments for regenerative processes, various recursive relations are obtained and are solved to derive important measures of the system performance.

These are as given below:

Expected up time of the system $\left(\mathrm{UT}_{0}\right) \quad=\mathrm{N}_{1} / \mathrm{D}_{1}$ Expected degraded time of the system $\left(\mathrm{DT}_{0}\right)=\mathrm{N}_{2} / \mathrm{D}_{1}$ Expected congestion time of the system $\left(\mathrm{CT}_{0}\right)=\mathrm{N}_{3} / \mathrm{D}_{1}$ Expected No. of inspections $\left(\mathrm{BI}_{0}\right)=\mathrm{N}_{4} / \mathrm{D}_{1}$ Expected no. of repairs $\left(\mathrm{BR}_{0}\right) \quad=\mathrm{N}_{5} / \mathrm{D}_{1}$

Where:

$$
\begin{aligned}
\mathrm{N}_{1}= & \mu_{0} \\
\mathrm{~N}_{2}= & \mathrm{p}_{02} \mu_{2}+\mathrm{p}_{02} \mathrm{p}_{28} \mu_{8}+\mathrm{p}_{02}\left(\mathrm{p}_{28} \mathrm{p}_{89}+\mathrm{p}_{29}\right) \mu_{9} \\
& +\mathrm{p}_{02}\left(\mathrm{p}_{28} \mathrm{p}_{89} \mathrm{p}_{910}+\mathrm{p}_{29} \mathrm{p}_{910}+\mathrm{p}_{210}\right) \mu_{10} \\
\mathrm{~N}_{3}= & \mathrm{p}_{03} \mu_{3} \\
\mathrm{~N}_{4}= & \mathrm{p}_{01} \mu_{1}+\mathrm{p}_{02} \mu_{2} \\
\mathrm{~N}_{5}= & \mathrm{p}_{01} \mathrm{p}_{14} \mu_{4}+\left(\mathrm{p}_{01} \mathrm{p}_{14} \mathrm{p}_{45}+\mathrm{p}_{01} \mathrm{p}_{15}\right) \mu_{5}+\left(\mathrm{p}_{01} \mathrm{p}_{14} \mathrm{p}_{45}\right. \\
& \left.+\mathrm{p}_{01} \mathrm{p}_{15}+\mathrm{p}_{01} \mathrm{p}_{16}\right) \mu_{6}+\mathrm{p}_{01} \mathrm{p}_{17} \mu_{7}+\left(\mathrm{p}_{01} \mathrm{p}_{14} \mathrm{p}_{45}\right. \\
& \left.+\mathrm{p}_{01} \mathrm{p}_{15}+\mathrm{p}_{01} \mathrm{p}_{16}\right) \mu_{6}+\mathrm{p}_{01} \mathrm{p}_{17} \mu_{7}+\mathrm{p}_{02} \mathrm{p}_{28} \mu_{8} \\
& +\left(\mathrm{p}_{02} \mathrm{p}_{28} \mathrm{p}_{89}+\mathrm{p}_{02} \mathrm{p}_{29}\right) \mu_{9}+\left(\mathrm{p}_{02} \mathrm{p}_{28} \mathrm{p}_{89}+\mathrm{p}_{02} \mathrm{p}_{29}\right. \\
& \left.+\mathrm{p}_{02} \mathrm{p}_{210}\right) \mu_{10} \\
\mathrm{D}_{1}= & \mu_{0}+\mathrm{p}_{01} \mu_{1}+\mathrm{p}_{02} \mu_{2}+\mathrm{p}_{03} \mu_{3}+\mathrm{p}_{01} \mathrm{p}_{14} \mu_{4} \\
& +\mathrm{p}_{01}\left(\mathrm{p}_{14} \mathrm{p}_{45}+\mathrm{p}_{15}\right) \mu_{5}+\mathrm{p}_{01}\left(\mathrm{p}_{14} \mathrm{p}_{45}+\mathrm{p}_{15}+\mathrm{p}_{16}\right) \mu_{6} \\
& +\mathrm{p}_{01} \mathrm{p}_{17} \mu_{7}+\mathrm{p}_{02} \mathrm{p}_{28} \mu_{8}+\mathrm{p}_{02}\left(\mathrm{p}_{28} \mathrm{p}_{89}+\mathrm{p}_{29}\right) \mu_{9} \\
& +\mathrm{p}_{02}\left(\mathrm{p}_{28} \mathrm{p}_{89}+\mathrm{p}_{29}+\mathrm{p}_{210}\right) \mu_{10}
\end{aligned}
$$




\subsection{Profit Analysis}

The expected profit incurred of the system is given by:

$$
\mathrm{P}=\mathrm{C}_{0} \mathrm{~A}_{0}+\mathrm{C}_{1} \mathrm{DT}_{0}+\mathrm{C}_{2} \mathrm{CT}_{0}-\mathrm{C}_{3} \mathrm{BI}_{0}-\mathrm{C}_{4} \mathrm{BR}_{0}-\mathrm{C}
$$

Where:

$\mathrm{C}_{0}=$ Revenue per unit uptime of the system

$\mathrm{C}_{1}=$ Revenue per unit degraded time of the system

$\mathrm{C}_{2}=$ Revenue per unit congestion time of the system

$\mathrm{C}_{3}=$ Cost per unit time of inspection

$\mathrm{C}_{4}=$ Cost per unit time of repair

$\mathrm{C}=$ Cost of installation of the system

\subsection{Graphical Interpretation}

For graphical analysis, following particular case is considered:

$$
\begin{aligned}
& \mathrm{g}_{\mathrm{h}_{1}}(\mathrm{t})=\beta_{\mathrm{h}_{1}} \mathrm{e}^{-\beta_{\mathrm{h}_{1}} \mathrm{t}} ; \\
& \mathrm{g}_{\mathrm{s}_{1}}(\mathrm{t})=\beta_{\mathrm{s}_{1}} \mathrm{e}^{-\beta_{\mathrm{s}_{1}} \mathrm{t}} ; \\
& \mathrm{g}_{\mathrm{h}_{3}}(\mathrm{t})=\beta_{\mathrm{h}_{3}} \mathrm{e}^{-\beta_{\mathrm{h}_{3}} \mathrm{t}} ; \\
& \mathrm{i}_{1}(\mathrm{t})=\alpha_{1} \mathrm{e}^{-\alpha_{1} \mathrm{t}} ; \\
& ; \mathrm{g}_{\mathrm{c}_{\mathrm{f}}}(\mathrm{t})=\beta_{\mathrm{c}_{\mathrm{f}}} \mathrm{e}^{-\beta_{\mathrm{c}_{\mathrm{f}} \mathrm{t}}}
\end{aligned}
$$

$$
\begin{aligned}
& \mathrm{g}_{\mathrm{h}_{2}}(\mathrm{t})=\beta_{\mathrm{h}_{2}} \mathrm{e}^{-\beta_{\mathrm{h}_{2}} \mathrm{t}} \\
& \mathrm{g}_{\mathrm{s}_{2}}(\mathrm{t})=\beta_{\mathrm{s}_{2}} \mathrm{e}^{-\beta_{\mathrm{s}_{2}} \mathrm{t}} \\
& \mathrm{g}_{\mathrm{h}_{4}}(\mathrm{t})=\beta_{\mathrm{h}_{4}} \mathrm{e}^{-\beta_{\mathrm{h}_{4}} \mathrm{t}} \\
& \mathrm{i}_{2}(\mathrm{t})=\alpha_{2} \mathrm{e}^{-\alpha_{2} \mathrm{t}}
\end{aligned}
$$

Various graphs for measures of system performances viz. MTSF, expected uptime, expected downtime, expected congestion time and profit are plotted for different values of rates of occurrence of faults, $\left(\lambda_{1}, \lambda_{2}\right.$, $\left.\lambda_{3}, \lambda_{4}\right), \quad$ probabilities of occurrence of hardware/software/hardware based software/catastrophic failure $\left(a_{1}, a_{2}, b_{1}, b_{2}, c_{1}, c_{2}, d_{1}\right)$, inspection rates $\left(\alpha_{1}, \alpha_{2}\right)$, hardware/software/hardware based software repair rate $\left(\beta_{\mathrm{h}_{1}}, \beta_{\mathrm{s}_{1}} \beta_{\mathrm{s}_{2}}, \beta_{\mathrm{h}_{3}} \beta_{\mathrm{h}_{4}}\right)$, catastrophic repair rate $\left(\beta_{\mathrm{c}_{\mathrm{f}}}\right)$ calls congestion and system restoration rates, $(\eta, \alpha)$.

Figure 2 gives the graph between MTSF $\left(\mathrm{T}_{0}\right)$ and rate of occurrence of major faults $\left(\lambda_{1}\right)$ for different values of rate of occurence of hardware based minor software fault $\left(\lambda_{4}\right)$. The graph reveals that MTSF decreases with increase in the value of the rate of occurrence of major faults. Further it can be observed that MTSF decreases with the decrease in the values of rate of occurrence of hardware based minor software faults.

Figure 3 gives the graph between expected uptime of the system $\left(\mathrm{UT}_{0}\right)$ and rate of occurrence of major faults $\left(\lambda_{1}\right)$ for different values of rate of occurrence of minor faults $\left(\lambda_{2}\right)$. The graph reveals that expected uptime of the system decreases with increase in the values of rate of occurrence of major faults as well as with the rate of occurrence of minor faults.
Figure 4 gives the graph between expected degraded time $\left(\mathrm{DT}_{0}\right)$ and rate of the minor faults $\left(\lambda_{2}\right)$ for different values of rate of occurence of hardware based minor software fault $\left(\lambda_{4}\right)$. The graph shows that expected degraded time of the system increases with increase in the values of the rate of minor faults as well as with the rate of occurence of hardware based minor software faults.

Figure 5 gives the graph between expected congestion time $\left(\mathrm{CT}_{0}\right)$ of the system and calls congestion rate $(\eta)$ for different values of restoration rate $(\alpha)$. The graph indicates that expected congestion time increases with increase in the values of rate of congestion of calls but decreases with increase in the values of restoration rate. The graph in Fig. 6 shows the pattern of profit $(\mathrm{P})$ with respect to the rate of occurrence of minor faults $\left(\lambda_{2}\right)$ for different values of rate of occurrence of hardware based minor software faults $\left(\lambda_{4}\right)$. The curve in the graph indicates that the profit of the system decreases with the increase in the values of the rates of occurrence of minor as well as hardware based minor software faults. Further from the graph it may also be noticed that for $\lambda_{4}=0.0023$ the profit is $>$ or $=$ or $<0$ according as $\lambda_{2}$ is $<$ or $=$ or $>0.007775$. Hence in this case the system is profitable to the company whenever $\lambda_{2}$ $\leq 0.007775$. Similarly, for $\lambda_{4}=0.0043$ and $\lambda_{4}=0.0063$, the profit is $>$ or $=$ or $<0$ according as $\lambda_{2}$ is $<$ or $=$ or $>0.004836$ and 0.003806 , respectively. Hence in these cases the system is profitable to the company whenever $\lambda_{2}$ $\leq 0.004836$ and 0.003806 , respectively.

The graph in Fig. 7 shows the pattern of profit $(P)$ with respect to the rate of occurrence of major faults $\left(\lambda_{1}\right)$ for different values of rate of occurrence of hardware based major software faults $\left(\lambda_{3}\right)$. The curve in the graph indicates that the profit of the system decreases with the increase in the values of the rates of occurrence of major as well as hardware based major software faults. Further from the graph it may also be noticed that for $\lambda_{3}=0.0001$ the profit is $>$ or $=$ or $<0$ according as $\lambda_{1}$ is $<$ or $=$ or $>0.268$. Hence the system is profitable to the company whenever $\lambda_{1} \leq 0.268$. Similarly, for $\lambda_{3}=0.1001$ and $\lambda_{3}=0.2001$, the profit is $>$ or $=$ or $<0$ according as $\lambda_{1}$ is $<$ or $=$ or $>0.191$ and 0.158 , respectively. Hence in these cases the system is profitable to the company whenever $\lambda_{1} \leq 0.191$ and 0.158 , respectively.

The graph in Fig. 8 shows the pattern of profit $(\mathrm{P})$ with respect to the revenue per unit degraded time of the system $\left(C_{1}\right)$ for different values of cost per unit repair of the system $\left(\mathrm{C}_{4}\right)$. The curve in the graph indicates that the profit of the system increases with the increase in the values of the revenue per unit degraded time but decreases with cost per unit repair time of the system. Further from the graph it may also be noticed that for $\mathrm{C}_{4}$ $=150$ the profit is $<$ or $=$ or $>0$ according as $C_{1}$ is $<$ or $=$ or $>308.948$. Hence the system is profitable to the company whenever $\mathrm{C}_{1} \geq 308.948$. 
Rajeev Kumar and Sunny Kapoor / Journal of Mathematics and Statistics 9 (3): 198-207, 2013

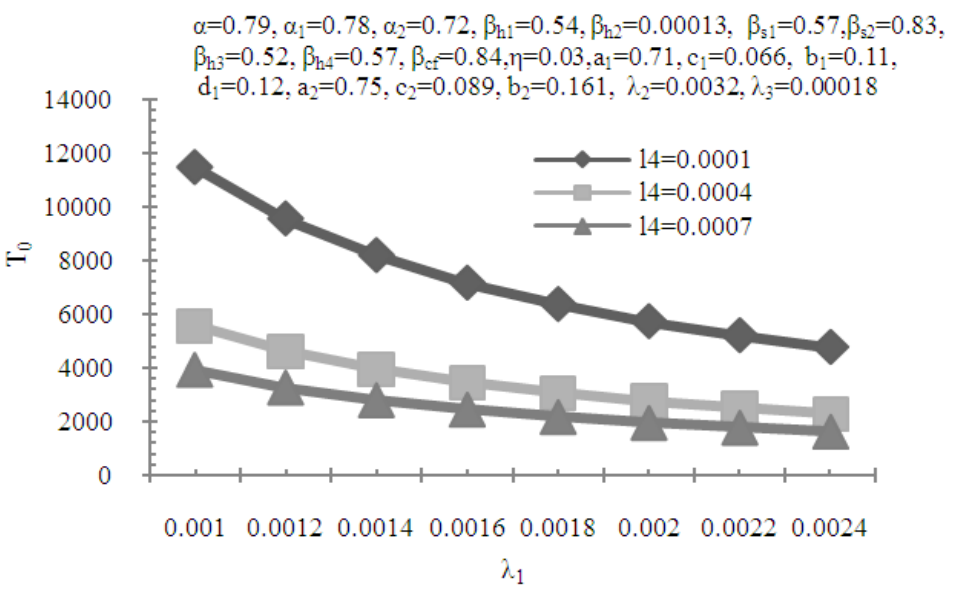

Fig. 2. MTSF V/S rate of major faults for different values of rate of hardware based minor software faults

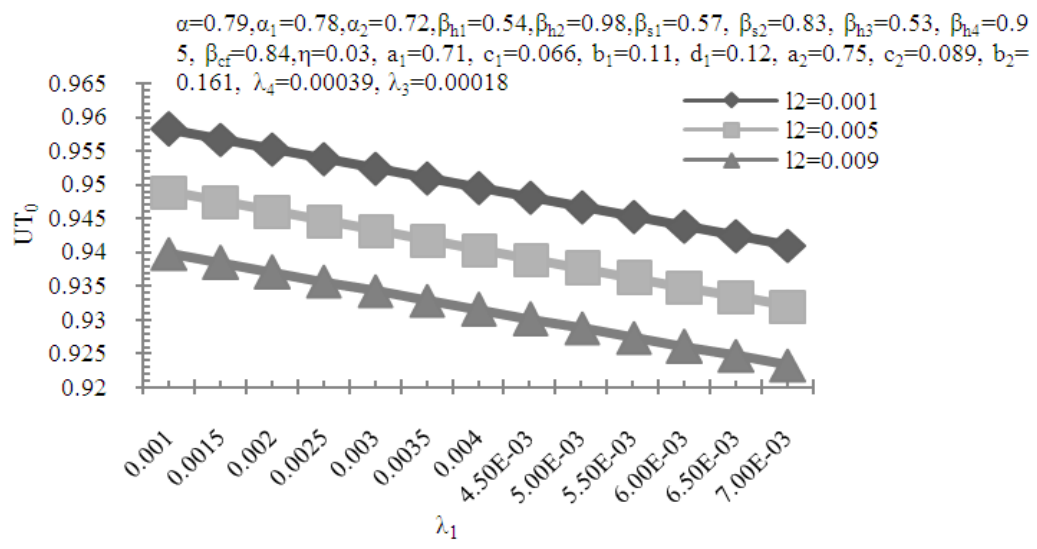

Fig. 3. Expected uptime V/S rate of major fault for different values of rate of minor faults

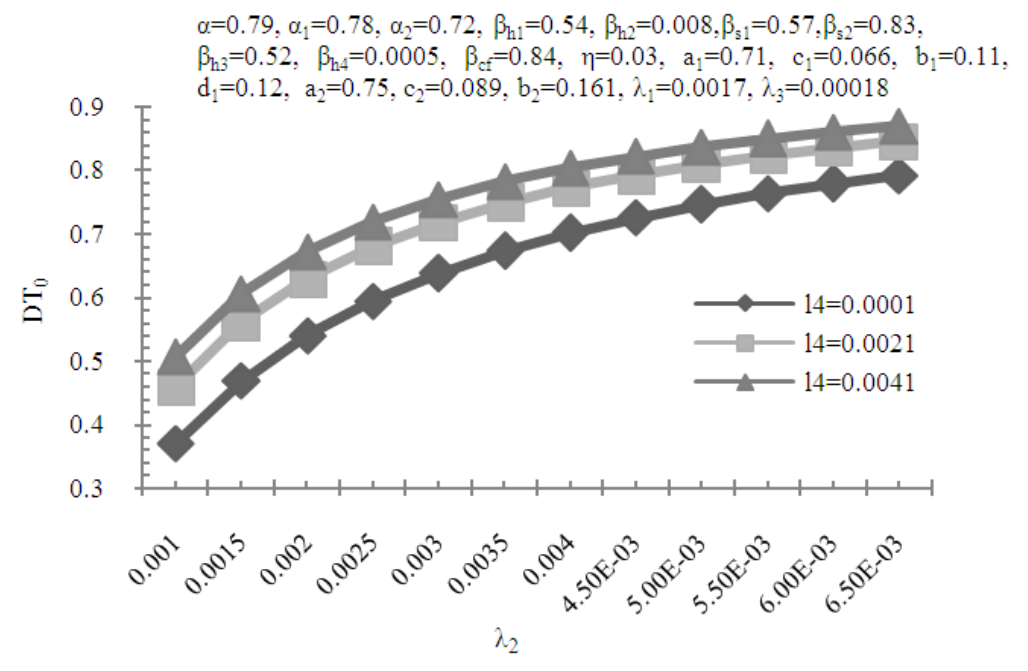

Fig. 4. Expected degraded time V/S rate of minor faults for different values of rate of hardware based minor software faults 
Rajeev Kumar and Sunny Kapoor / Journal of Mathematics and Statistics 9 (3): 198-207, 2013

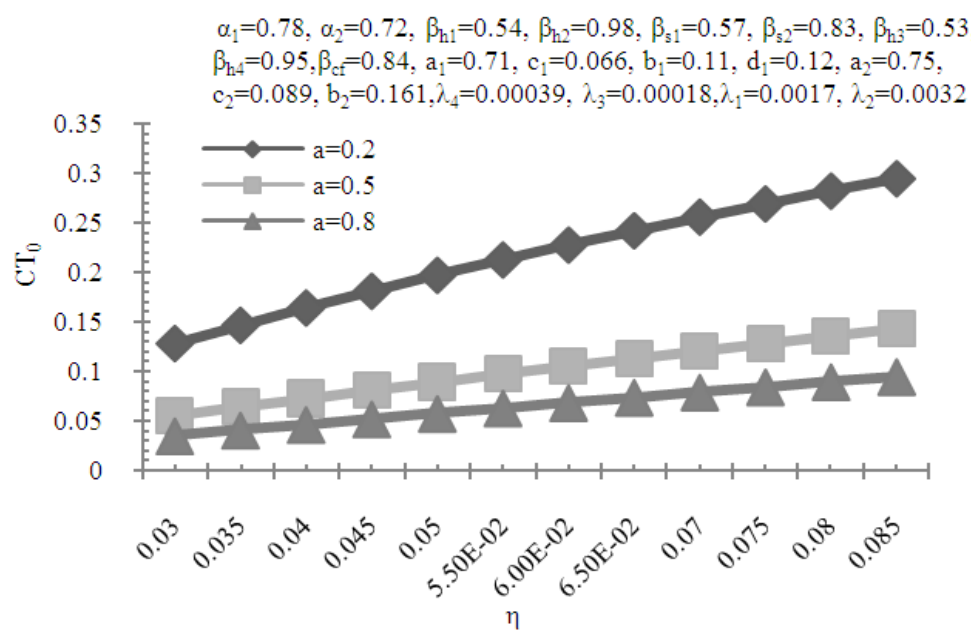

Fig. 5. Expected congestion time V/S rate of congestion for different values of restoration rate

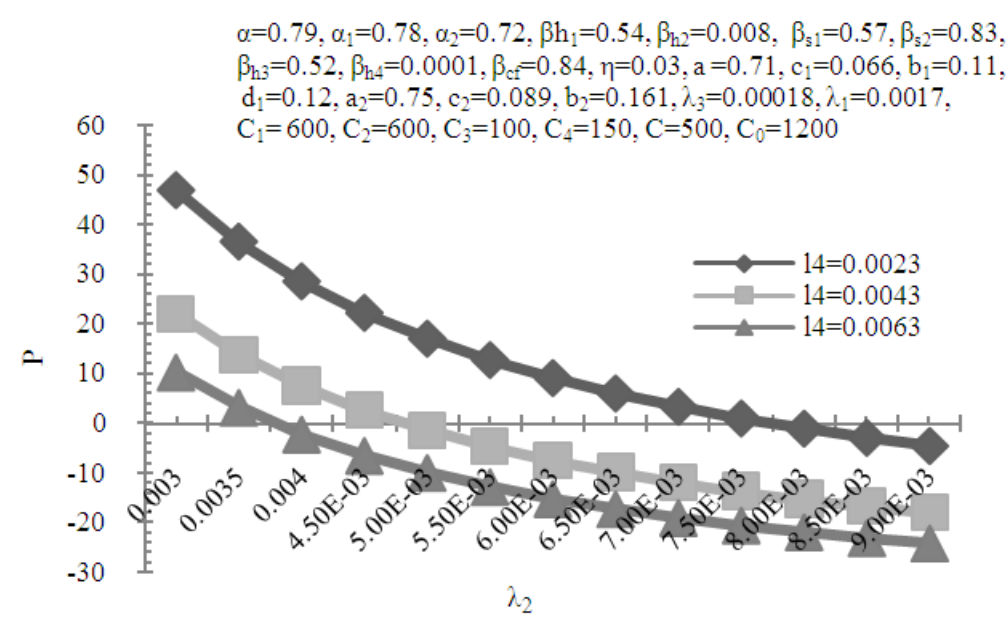

Fig. 6. Profit V/S rate of minor faults for different values of rate of hardware based minor software faults

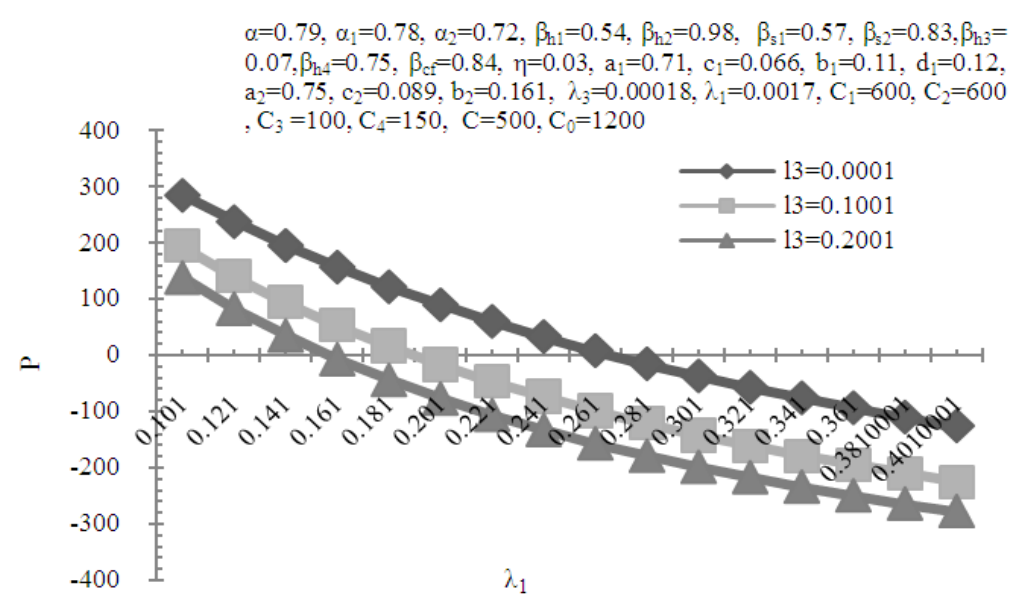

Fig. 7. Profit V/S rate of major faults for different values of rate of hardware based major software faults 


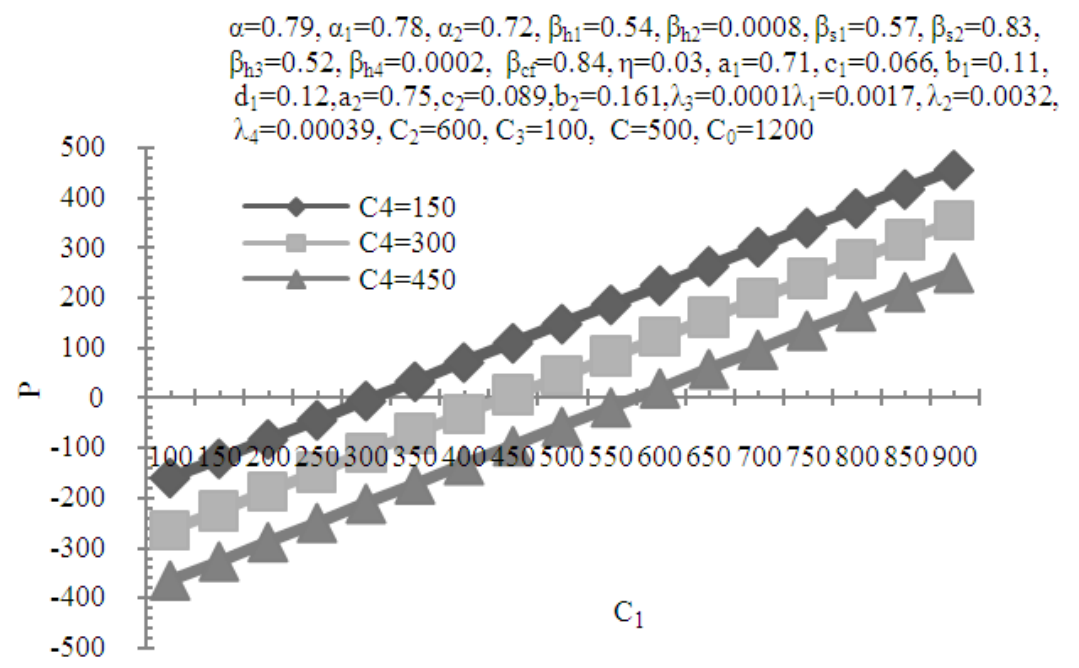

Fig. 8. Profit V/S revenue per unit degraded time of the system for different values of cost per unit repair time of the system

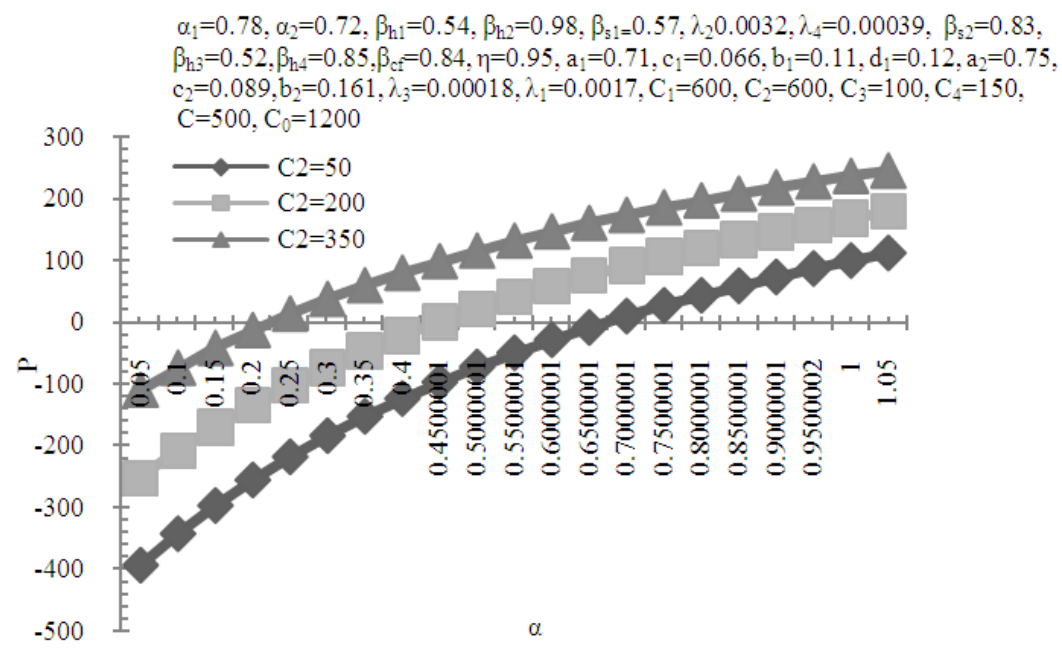

Fig. 9. Profit V/S rate of restoration of calls for different values of revenue per unit congestion time of the system

Similarly, for $\mathrm{C}_{4}=300$ and $\mathrm{C}_{4}=450$, the profit is $<$ or $=$ or $>0$ according as $\mathrm{C}_{1}$ is $<$ or $=$ or $>442.137$ and 575.325 , respectively. Hence in these cases the system is profitable to the company whenever $C_{1} \geq 442.137$ and 575.325 , respectively.

The graph in Fig. 9 shows the pattern of profit $(\mathrm{P})$ with respect to the rate of restoration from congestion $(\alpha)$ for different values of revenue per unit congestion time of the system $\left(\mathrm{C}_{2}\right)$. The curve in the graph indicates that the profit of the system increases with the increase in the values of rate of restoration as well as with the revenue per unit congestion time of the system. Further from the graph it may also be noticed that for $\mathrm{C}_{2}=50$ the profit is $\langle$ or $=$ or $\rangle$ 0 according as $\alpha$ is $<$ or $=$ or $>0.671$. Hence the system is profitable to the company whenever $\alpha \geq 0.671$. Similarly, for $\mathrm{C}_{2}=200$ and $\mathrm{C}_{2}=350$, the profit is $\langle$ or $=$ or $>0$ according as $\alpha$ is $<$ or $=$ or $>0.447$ and 0.224 , respectively. Hence in these cases the system is profitable to the company whenever $\alpha \geq 0.447$ and 0.224 , respectively.

The curve in the Fig. 10 shows the behavior of the profit $(\mathrm{P})$ with respect to the revenue per unit up time $\left(\mathrm{C}_{0}\right)$ of the system for the different values of rate of software based minor hardware faults $\left(\lambda_{4}\right)$. It is evident from the graph that profit increases with the increase in the values of revenue per unit up time of the system for a fixed value of the rate of occurrence of software based major hardware faults. 


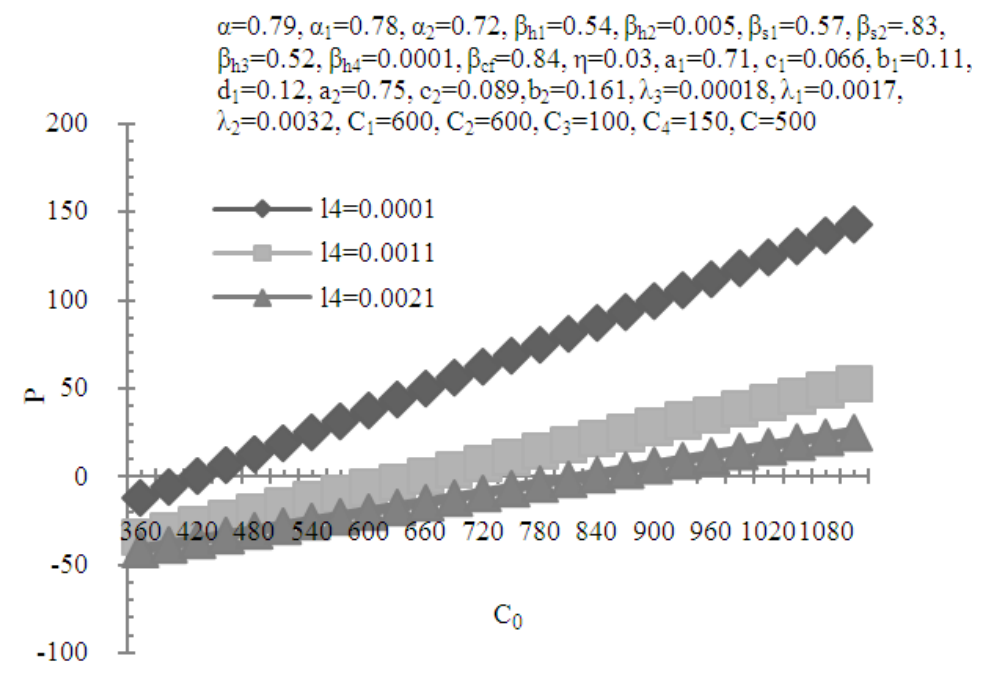

Fig. 10. Profit V/S revenue per unit uptime of the system for different values of rate of hardware based minor software faults

From the Fig. 10 it may also be observed that for $\lambda_{4}=$ 0.0001 , the profit is $>$ or $=$ or $<0$ according as $\mathrm{C}_{0}$ is $>$ or $=$ or $<$ Rs.420.499. Hence the system is profitable to the company whenever $C_{0} \geq$ Rs.420.499. Similarly, for $\lambda_{4}=$ 0.0011 and $\lambda_{4}=0.0021$ the profit is $>$ or $=$ or $<0$ according as $\mathrm{C}_{0}$ is $>$ or $=$ or $<$ Rs.656.095 and Rs.825.326 respectively. Thus, in these cases, the system is profitable to the company whenever $\mathrm{C}_{0} \geq \mathrm{Rs} .656 .095$ and Rs. 825.326, respectively.

\section{CONCLUSION}

From the graphical analysis it may be concluded that the Mean Time to System Failure (MTSF) and expected uptime of the BTS decreases with the increase in the values of the rates of occurrence of major as well as minor hardware/software faults. Further it is observed that the MTSF and expected uptime decreases with the increase in the rate of occurrence of hardware based software faults. These also decrease with the increase in the probability of occurrence of major and minor faults.

On the other hand, the expected degraded time of the BTS increases with the increase in the rates of occurrence of major and minor hardware/software faults and also with hardware based software faults and the expected congestion time increases with the increase in values of the calls congestion rate and decreases with the values of rate of increase in restoration from congestion.

The profit of the system increases with the increase in the values of revenue per unit up time, degraded time and congestion time of the system and rate of restoration from congestion but decreases with increase in cost per unit inspection time and repair time of the system. Further decreases with rates of occurrence of major and minor hardware/software faults and also decreases with rate of occurrence of hardware based software faults. Various cutoff points for revenue per unit uptime, rate of occurrence of major and minor faults can be obtained. Also for fixed values of revenue per unit congestion time of the system, cutoff points for rate of restoration from calls can be obtained. For fixed values of cost per unit repair time of the system, cutoff points for revenue per unit degraded time of the system can also be obtained.

\section{REFERENCES}

Gopalan, M.N. and K.S. Bhanu, 1995. Cost analysis of a two unit repairable system subject to on-line preventive maintenance and/or repair. Microelect. Reliab., 35: 251-258. DOI: 10.1016/0026-2714(95)90090-D

Gopalan, M.N. and N.N. Murlidhar, 1991. Cost analysis of a one-unit repairable system subject to on-line preventive maintenance and/or repair. Microelect. Reliab., 31: 223-228. DOI: 10.1016/00262714(91)90203-J

Gupta, M.L. and A. Kumar, 1983. On profit consideration of a maintenance system with minor repair. Microelect. Reliab., 23: 437-439. DOI: 10.1016/0026-2714(83)91168-X

Kumar, R. and P. Bhatia, 2011. Reliability and cost analysis of one unit centrifuge system with single repairman and inspection. Pure Applied Math. Sci., 74: 113-121. 
Kumar, R. and S. Kapoor, 2012. Cost-benefit analysis of reliability model for a base transceiver system considering hardware/software faults and congestion of calls. Int. J. Adv. Sci. Technol., 4: 13-23.

Kumar, R. and S. Kapoor, 2013. Profit evaluation of a stochastic model on base transceiver system considering software based hardware failures and congestion of calls. Int. J. Applic. Innovat. Eng. Manage., 2: 554-562.

Kumar, R. and S. Rani, 2013. Cost-benefit analysis of a reliability model on water process system having two types of redundant subsystems. Int. J. Applied Math. Res., 2: 293-302.

Kumar, R., S.S. Mor and M.K. Sharma, 2010. Reliability and cost benefit analysis of a three stage operational warranted sophisticated system with various minor and major faults. Pure Applied Math. Sci., 72: 29-38.
Rizwan, S.M. and G. Taneja, 2000. Profit analysis of system with perfect repair at partial failure or complete failure. Pure Applied Math. Sci., LII: 7-14.

Taneja, G., V.K Tayagi and P. Bhardwaj, 2004. Profit analysis of single unit programmable logic controller. Pure Applied Math. Sci., LX: 55-71.

Teng, X., H. Pham and D.R. Jeske, 2006. Reliability modeling of hardware and software interactions and its applications. IEEE Trans. Reliab., 55: 571-577. DOI: 10.1109/TR.2006.884589

Tumer, I.Y. and C.S. Smidts, 2011. Integrated designstage failure analysis of software-driven hardware systems. IEEE Trans Comput., 60: 1072-1084. DOI: 10.1109/TC.2010.245

Welke, S.R., B.W. Johnson and J.H. Aylor, 1995. Reliability modeling of hardware/software systems. IEEE Trans. Reliab., 44: 413-418. DOI: $10.1109 / 24.406575$ 